\title{
Simulation of Annual Functionality of Roof Turbine Ventilator
}

\author{
Giedrè Streckienè, Violeta Motuzienè, Dovydas Rimdžius, Vytautas Martinaitis ${ }^{1}$ and Juozas Bielskus \\ Department of Building Energetics, Vilnius Gediminas Technical University, Vilnius, Lithuania
}

\begin{abstract}
Ventilation systems using renewable energy enable to reduce electricity demand. However, their operation directly depends on the stability of the renewable energy source. In this study, the wind driven roof turbine ventilator (RTV) is analysed. As a rule, this equipment is selected based only on the average annual wind speed and there exists a lack of date related to functionality of RTV. The case study presented in the paper seeks to assess functional operation of the RTV within the whole year. Simulations, performed with TRNSYS software, are based on the empirical equation for the ventilation flow rate extracted by the tested turbine ventilator. Results provide the number of RTV operational hours and share (\%) of the time, when the RTV operates. Most of the time RTV operates at partial required load, however, there are periods when air flow rates are excessive and this should be considered as storage potential. The presented results could help to determine more accurately functional operation of RTV in the selected room/building and estimate demand for additional ventilation solutions as well energy storage potential.
\end{abstract}

\section{Introduction}

Despite that a growing number of countries have put in place policies to improve building energy performance, average energy consumption per person in the global buildings sector still remains practically unchanged since 1990 [1]. Assertive action is needed now across all countries to improve global average energy use per capita by at least $10 \%$ by 2025 using energy-efficient and lowcarbon building technologies and this is possible without changing comfort levels or requiring households to reduce their purchases of appliances and other electronic equipment [2].

In building's sector main energy consumers are heating and cooling systems. They consume half of the European Union's (EU) energy and much of it is wasted [3]. The EU has set itself a long-term goal of reducing greenhouse gas emissions by $80-95 \%$, when compared to 1990 levels, by 2050. Renewable heating and cooling are vital to decarbonisation [4].

Ventilation is the key issue for providing suitable indoor air quality (IAQ). This can be done either using fans - mechanical ventilation, or without interaction of any mechanical means - natural ventilation. Mechanical ventilation generally uses electricity in order to provide proper ventilation rate. As Chenari et al. [5] have shown in their review paper - up to $90 \%$ of fans electricity can be saved using natural ventilation. Therefore, natural ventilation is now one of the fundamental methods in the energy efficient design of buildings.

The two fundamental principles of natural ventilation are stack effect and wind driven ventilation. Rooftop turbine ventilator (RTV) is one of the wind driven ventilation devices, which is cost effective and environmentally friendly, used to extract airflow from a building [6]. A RTV is a wind-driven air extractor which combines features of wind turbine and extract fan. RTV is not only widely accepted as industrial ventilation, but also has become a common ventilation feature used in other types of buildings including institutional, commercial and residential [7].

There is a significant number of studies related to the experimental measurements or CFD simulations of RTV. Some of them are concentrating on the influence of height [6] or diameter [8], [9] on performance of the ventilator, the others - on different constructions and/or blades [10] or actual applications in buildings and improvement of IAQ [11]. Newer tendencies of research in the field of RTV are related to additional benefits production of electricity using RTV [12], [13] or exploitation of solar energy to increase the efficiency of the device [14], [15]. Also, some studies show that wind driven ventilators can play an important role in the design of a cost effective and energy efficient ventilation system inside a building as they have low cost, require no maintenance and no electricity to run $[6,8,11]$.

The aim of the study presented in the paper is to define annual ventilation efficiency of the room and potential for energy storage at local climate conditions, using TRNSYS simulation model, based on experimentally defined ventilator's performance curve. Simulations are performed for 6 different European cities with different climate conditions.

\section{Methodology}

This study analyses functionality of RTV for different local conditions. The turbine ventilator used in this investigation is $\mathrm{H} 100$ (Hurricane ${ }^{\circledR}$ ) produced by 
Edmonds ${ }^{\circledR}[16]$. It is constructed from corrosion resistant aluminium and consists of a rotating portion (Rotor) with 8 curved blades and a stationary portion - base of cylindrical shape. The dimensions of this RTV are shown in Fig. 1. A rotating RTV can be compared to a vertical axis wind turbine in its rotor configuration and in the sense that it also uses wind energy directly for its rotation [17].

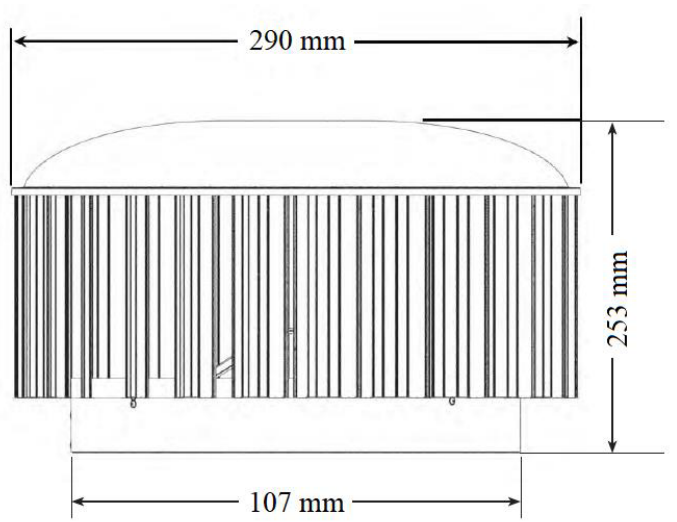

Fig. 1. Schema of analysed RTV.

Seeking to analyse functionality of the certain RTV, following steps must be performed:

1. Collection of the required model input data:

- Definition of the building type, area, requirements for the IAQ;

- Wind speed data for the analysed locations (if meteorological station is not at the analysed location, additional evaluation of the wind speed is required). In this analysis wind speed data in height of $10 \mathrm{~m}$ is used (from Meteonorm tm2 file);

- RTV properties (dependency of the extracted air flow rate on wind speed) are required. When exact location of the RTV on the roof is known, additional coefficient to assess impact of the roof shape on the performance of RTV can be introduced. For this CFD simulation would be required. This study, does not take into account influence of the roof construction.

2. Creating the model in TRNSYS software, including all input data and system's/device's evaluation criteria. In this step also simulation time period (1 year) and step (1 min.) are defined.

3. Simulation and analysis of the results. Output data of the simulation at each time step is processed and used further for the RTV's operation efficiency evaluation within the year. If analysis shows that RTV is not able to ensure proper IAQ for the defined period, model input data must be changed, e.g. another RTV can be chosen or number of RTV's increased.

A theoretical warehouse room of $50 \mathrm{~m}^{2}$ floor area is chosen as a case study. It is assumed that thermal comfort criteria are satisfied and only ventilation rates are analysed which are independent on season. This analysis assumes the minimum ventilation air flow rates in breathing zone based on ASHRAE Standard [18] $0.3 \mathrm{l} /\left(\mathrm{s} \mathrm{m}^{2}\right)$ for the warehouses. The outdoor airflow required in the breathing zone of space in a ventilation zone is assumed to be equal to extracted airflow. In accordance with [18], air flow rate is determined to be $15 \mathrm{l} / \mathrm{s}$ for the warehouse space as normally it is unoccupied.

In this analysis, stack effect is neglected, just wind caused ventilation effect is evaluated as stack effect depends a lot on building internal temperature, geometry, location and size of the air supply openings. RTV's operation functionality is evaluated based on two criteria: 1) number of RTV operational hours and 2) share (\%) of the time, when the RTV operates. For the base case simulations weather data for Vilnius (Lithuania) is used. Additionally, five biggest EU cities - London, Berlin, Madrid, Rome and Paris are simulated for the comparison of the RTV's operation in different locations. Tm2 weather data files (Meteonorm data in TRNSYS software) are employed in simulations.

Possible extracted air flow rates from the warehouse room are modelled by TRNSYS v. 17 software. The software has a modular structure with a main visual interface. The main components of the system are described below and presented in Fig. 2.

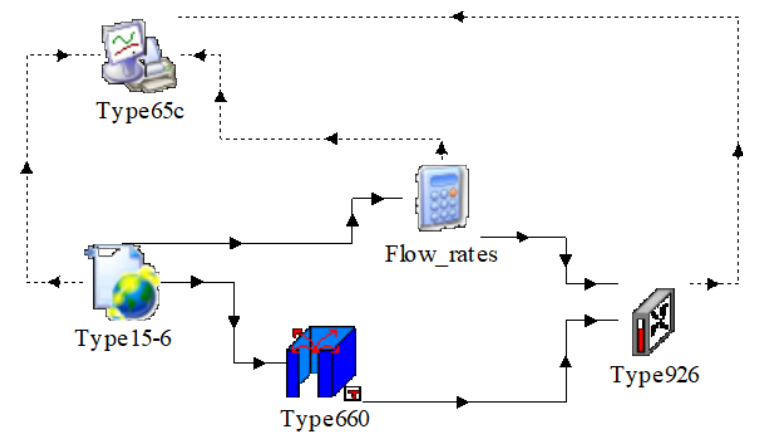

Fig. 2. TRNSYS model.

Type15-6 is weather data processor used to determine local climatic conditions. Type660 is multi-zone building model component. It enables to describe ventilated space. Type926 is a component for variable speed fan. Type65c is graphical plotter with output file enabling to analyse calculation results and "Flow_rates" is type to insert equations.

The main equation used in this study is based on experiments executed in the Laboratory of Buildings Energy and Microclimate Systems in Vilnius Gediminas Technical University for the exact type of RTV. The extracted air flow rate $\left(\mathrm{m}^{3} / \mathrm{h}\right)$ is simulated in TRNSYS using experimental equation:

$$
V_{e x}=0.0185 \cdot v^{2}+11.819 \cdot v-6.3174,
$$

where $v$ is a wind speed, $\mathrm{m} / \mathrm{s}$.

It was defined by experiment, that the minimum wind speed of $2 \mathrm{~m} / \mathrm{s}$ is required to start operation of the analysed RTV to extract air using only wind energy (stack effect is not included).

\section{Results and discussion}




\subsection{Base case study - Vilnius city}

The comparison between simulated flow rate extracted by turbine ventilator and total required ventilation flow rate $(15 \mathrm{l} / \mathrm{s})$ against wind speed is shown in Fig. 3. It is evident that wind speed of $5.1 \mathrm{~m} / \mathrm{s}$ enables RTV to extract total required ventilation air flow rate for the studied room. The area above $100 \%$ shows wind energy storage potential. The stored energy could be used for the periods when wind speed is low.

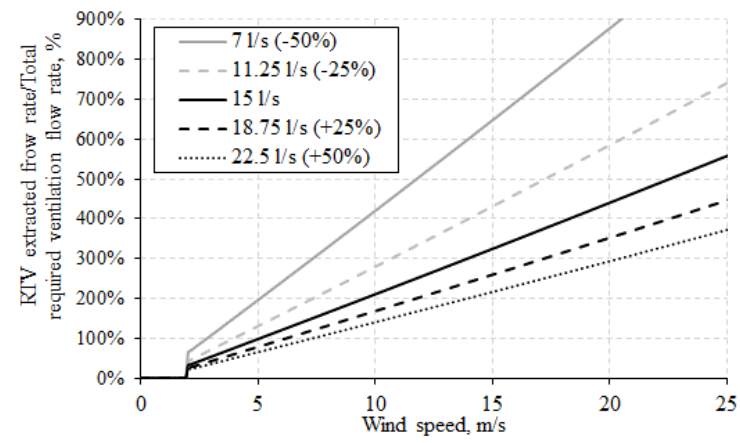

Fig. 3. Comparison between the flow rate extracted by RTV and total required ventilation flow rate vs wind speed.

Fig. 3. also shows sensitivity of the results on the required ventilation demand, e.g. if we reduce area of the room or use more turbine ventilators, a higher share of extracted air flow rate could be achieved. For the floor area of $25 \mathrm{~m}^{2} \mathrm{RTV}$ could extract total ventilation flow rate $(7 \mathrm{l} / \mathrm{s})$ at wind speed of $2.9 \mathrm{~m} / \mathrm{s}$. However, higher flow rates, e.g. $18.75 \mathrm{l} / \mathrm{s}$ or $22.5 \mathrm{l} / \mathrm{s}(+25 \%$ or $50 \%$ of the case study) will need wind speed of $6.2 \mathrm{~m} / \mathrm{s}$ and $7.4 \mathrm{~m} / \mathrm{s}$, respectively.

Analysis of annual operation of RTV in a warehouse room of $50 \mathrm{~m}^{2}$ in Vilnius city shows that RTV can fully cover required ventilation demand $\sim 2218 \mathrm{~h} /$ year $(25.3 \%$ of the time). Also, during this time period RTV could extract more air than needed (has energy storage potential). It is calculated, that this unit does not operate $2325 \mathrm{~h} /$ year $(\sim 26.5 \%)$ at all and other technological solutions are needed when wind speed is less than $2 \mathrm{~m} / \mathrm{s}$. Most of the time RTV operates at the partial performance (48.2\% of time).

When RTV operates at partial required performance, it can cover from 30 to $100 \%$ of the ventilation demand (Fig. 4), at the wind speeds varying from $2 \mathrm{~m} / \mathrm{s}$ to $5 \mathrm{~m} / \mathrm{s}$. At the low wind speeds $(<2 \mathrm{~m} / \mathrm{s})$, RTV practically does not operate, therefore low air flow rates are not extracted ( $0-30 \%$ of total ventilation air flow rate).

From Fig. 4, it is obvious that most of the time RTV extracts $30-80 \%$ of the total ventilation rate $(15 \mathrm{l} / \mathrm{s})$ as the wind speed in Vilnius usually fluctuates between $2 \mathrm{~m} / \mathrm{s}$ and $4 \mathrm{~m} / \mathrm{s}$. To satisfy higher extracted air flow rates, more units for the same floor area must be designed.

Fig. 5 shows detailed analysis of the partial extraction of air flow. Lower columns in Fig. 5 show that when the time of partial operation mode of RTV decreases, the RTV can extract all required air flow rate. If we have a situation, when air flow rate is twice higher $\left(0.6 \mathrm{l} / \mathrm{s} / \mathrm{m}^{2}\right)$, it is seen that most time of the year RTV extracts just 10$50 \%$ of the required air flow rate. Meanwhile, when ventilation demand is twice lower, RTV operates at full required performance most of the time.

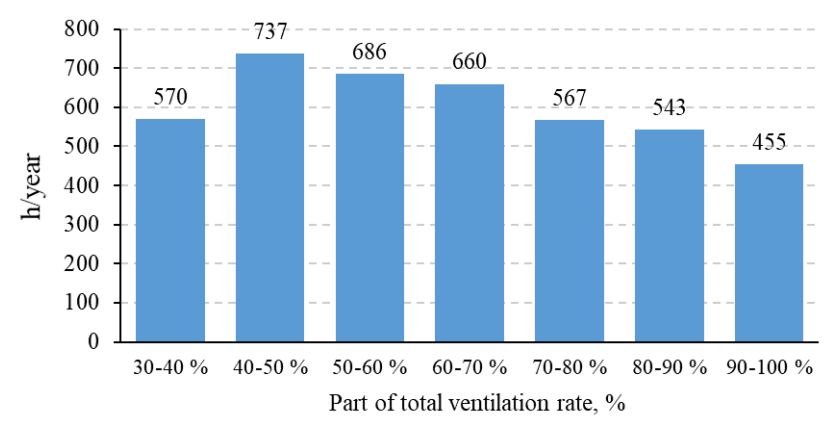

Fig. 4. RTV part load operation duration (h/year).

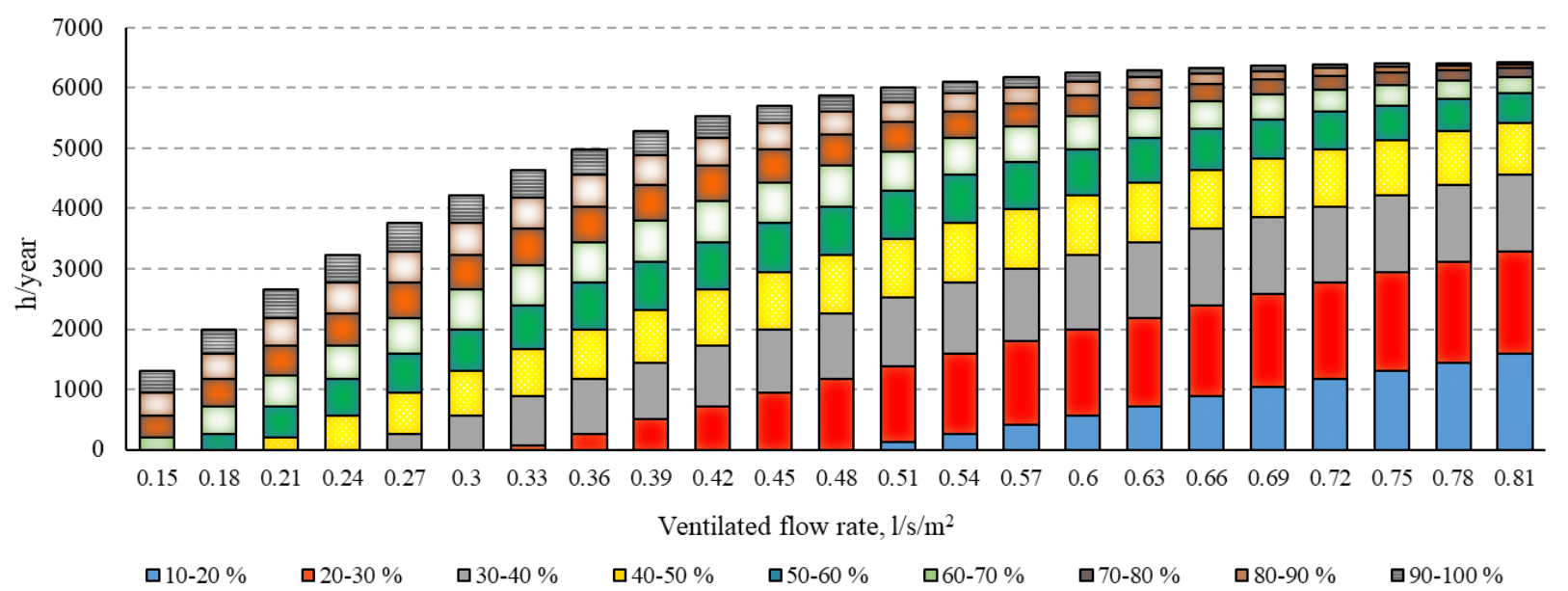

Fig. 5. Dependency of the RTV part load operation on required air flow rates

The dependency of extracted (fully and partially) ventilation air flow rate on required ventilation flow rate $\left(1 / \mathrm{s} / \mathrm{m}^{2}\right)$ is presented in Fig. 6. When wind speed is $\leq$ $2 \mathrm{~m} / \mathrm{s}$, RTV does not extract the air. Meanwhile, fully $(100 \%)$ satisfied extracted ventilation air flow rate increases almost exponentially when ventilated flow rate decreases in the range from $0.71 / \mathrm{s} / \mathrm{m}^{2}$ to $0.1 \mathrm{1} / \mathrm{s} / \mathrm{m}^{2}$ (Fig. 6). At the same time, the partial extracted flow rate by RTV decreases. 


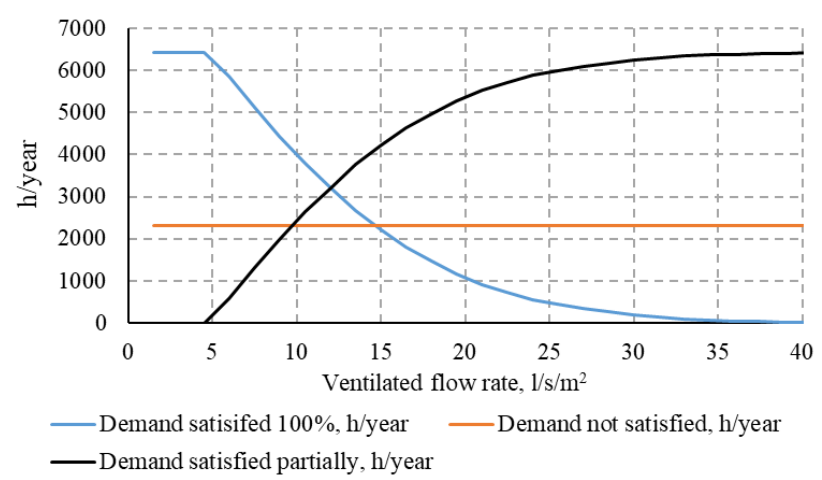

Fig. 6. Dependency of fully and partially ventilation flow rate by RTV on required ventilation flow rate.

Analogous charts as Fig. 5 and Fig. 6 could be used to determine operation duration of RTV for the specified volume of the room.

\subsection{Comparison of RTV operation in other EU cities}

As the main RTV operation efficiency influencing parameter is wind speed, its duration time ( $\mathrm{h} /$ year) in different EU capitals is presented in Fig. 7. From this figure it is obvious that Madrid is characterized by low wind speeds, Vilnius and London have similar wind speeds. Paris and Berlin have the highest wind speeds in comparison with other analysed cities.

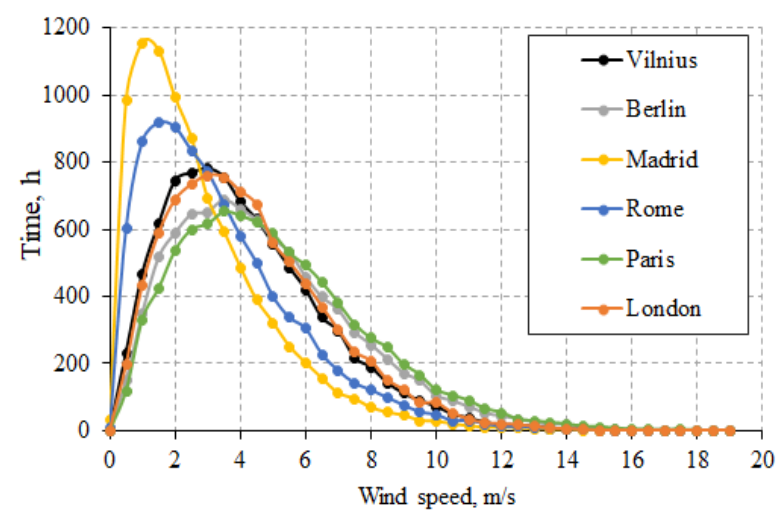

Fig. 7. Analysis of wind speed in different cities.

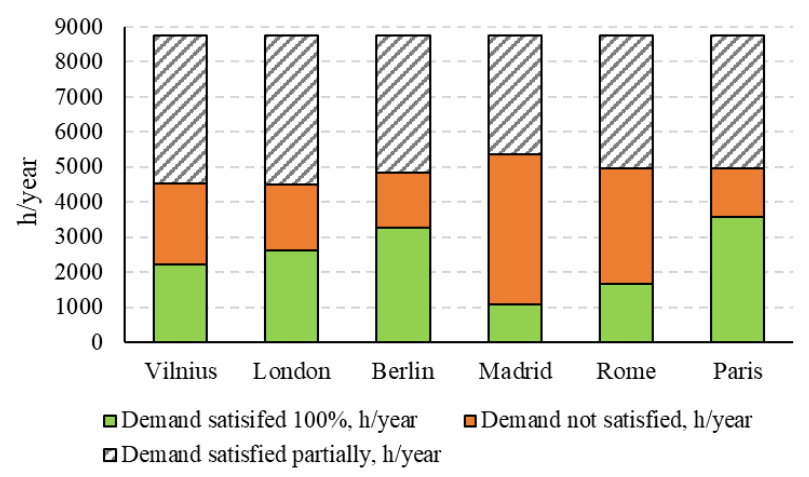

Fig. 8. Comparison of RTV operation in six EU capitals.
Knowing the actual operation of the RTV and wind speed in a certain location enables to evaluate operation duration of the ventilator in different modes (Fig. 8).

Fig. 8 clearly shows - if analysed RTV uses only wind kinematic energy, Madrid has the worst results for RTV operation ( $48.9 \%$ of the time the RTV does not use wind speed energy) and Paris - the best ones (only 15.9\% of the time is not satisfied). Respectively, not satisfied time (h/year) by the RTV is $26.5 \%$ in Vilnius, $21.6 \%$ in London, $18.1 \%$ in Berlin and $37.4 \%$ in Rome. These values show that the same RTV unit cannot be chosen for the same purposes in different geographical locations. Also, partial operation mode together with full operation mode $(100 \%$ and more of need is satisfied) should be analysed for energy storage possibilities.

Even though average wind speed in the cities can be similar, annual distributions differ. This causes differences in RTV's annual functionality. For example, about 570-590 h/year the RTV in Vilnius and Rome extracts only the $30-40 \%$ of the total ventilation flow rate. Meanwhile, the RTV in Paris operates only $423 \mathrm{~h}$ for the same extracted flow rate. For the highest extracted flow rates $(90-100 \%)$, Paris is leading $(518 \mathrm{~h} /$ year $)$, respectively, Berlin has 504 h/year, London - 489 h/year, Vilnius - $455 \mathrm{~h} /$ year, Rome - $349 \mathrm{~h} /$ year and Madrid only $271 \mathrm{~h} /$ year. It is simulated that RTV could extract more air than required from $12 \%$ (Madrid) to $41 \%$ (Paris) time of the year.

The further step of this analysis will be evaluate stack effect of natural ventilation when the RTV does not operate at low wind speed and introduce variable ventilation flow rates.

\section{Conclusions}

A study of a roof turbine ventilator functional operation using TRNSYS simulation and empirical correlation for air flow rates has been carried out. The influence of wind conditions in six EU's cities on the flow rate extraction has been discussed. Results show that the same RTV unit cannot be used for the same purposes in different locations as there is strong influence of wind speed on extracted air flow rates. Case study of the warehouse room shows that for different locations using just kinetic energy of wind, RTV is able to extract more air than required from $12 \%$ to $41 \%$ time of the year. As a perspective, storage technologies could be used during this time period. It has also been found that RTV cannot use wind energy from 15.9\% (Paris) till 48.9\% (Madrid) of the time for the selected cities. Most time of the year RTV operates just at the partial required performance and does not satisfy required ventilation air flow rates. At these periods, auxiliary energy systems (e.g. mechanical ventilators) are required or stored wind energy can be employed.

As a future work, the proposed model can be improved and adapted for the buildings/rooms where there is no demand for permanent ventilation and there exists a potential to utilize stored wind energy.

\section{Acknowledgement}


This research is funded by the European Regional Development Fund according to the supported activity 'Research Projects Implemented by World-class Researcher Groups' under Measure No. 01.2.2-LMT-K718 (project grant No 01.2.2-LMT-K-718-01-0016).

\section{References}

1. IEA, Energy efficiency indicators (2017).

2. IEA, Transition to Sustainable Buildings, Paris (2013).

3. European Comission, An EU Strategy on Heating and Cooling 2016, Brussels (2016).

4. European Comission, Energy Roadmap, 2050, Brussels (2011)

5. B. Chenari, J. D. Carrilho, and M. Gameiro, Sustain. Energy Rev., 59, 1426-1447 (2016).

6. S. J. Lien and N. A. Ahmed, Build. Environ., 45, 1808-1815 (2010).

7. M. Ismail, A. Malek, and A. Rahman, J. Sust. Development, 5, 121-131 (2012).

8. G. K. Jadhav, P. M. Ghanegaonkar, and S. Garg, Journal of Building Engineering, 6, 196-202 (2016).

9. C. Lai, Energy Build., 35, 188, 927-932 (2003).
10. N. Khan, Y. Su, S. B. Riffat, and C. Biggs, Renew. Energy, 33, 2441-2447 (2008).

11. J. Lien and N. Ahmed, Procedia Engineering, 49, 124-134 (2012).

12. C. Torasa and N. Sermsri, Procedia - Social and Behavioral Sciences, 197, 1690-1696 (2015).

13. R. Shinde, V. Lavhale, A. Nair, S. Pawar, and R Mahajan, Int. $\mathrm{J}$ of Current Engineering and Technology, 6, 89-93 (2016).

14. P. Valeh-e-sheyda, M. Rahimi, A. Parsamoghadam, and M.M. Masahi, Energy Build., 73, 115-119 (2014).

15. A. Suresh, B. Jacob, L. F. Sharaf, and S. Gomathy, IOSR Journal of Electrical and Electronical Engineering, 88-91 (2017).

16. Hurricane $₫$ Roof mounted ventilators online: last access 08-05-2018. https://www.edmonds.com.au/commercial-industrialventilation/auditoriums/hurricane/specifications

17. P. M. Pardalos, S. Rebennach, M. V. F. Pereira, N. A Iiadis. Handbook of Wind Power Systems. Springer. (2013).

18. ASHRAE Standard 62.1-2013. Ventilation for Acceptable Inddor Air Quality (2013). 